\title{
Phylogenetic analysis and systematic position of two new species of the ant genus Crematogaster (Hymenoptera, Formicidae) from Southeast Asia
}

\author{
Shingo HOSOISHI ${ }^{1, *} \&$ Kazuo OGATA ${ }^{2}$ \\ 1,2 Institute of Tropical Agriculture, Kyushu University, \\ 6-10-1 Hakozaki, Higashi-ku, Fukuoka, 812-8581 Japan. \\ *Corresponding author: hosoishi@gmail.com \\ ${ }^{2}$ Email: kogata@agr.kyushu-u.ac.jp \\ ${ }^{1}$ urn:1sid:zoobank.org:author:75C51C3B-5C72-4229-8599-6AE254086690 \\ ${ }^{2}$ urn:lsid:zoobank.org:author:2A3EC860-EE95-4D5F-AAEC-E87838815AFF
}

\begin{abstract}
Two distinct new species of the ant genus Crematogaster, C. khmerensis sp. nov. and C. pfeifferi sp. nov., are described from Cambodia and Malaysia, respectively. The two species are unique among Asian Crematogaster in that they have vertically directed propodeal spines, but their systematic positions have not been determined based on morphological characters alone. Molecular phylogenetic analysis of 89 Crematogaster taxon matrices previously published plus C. khmerensis sp. nov., using nuclear genes, reveals that $C$. khmerensis sp. nov. is nested within the Australo-Asian Crematogaster clade. Morphological assignment of the developed pronotal shoulders implies a close relationship between $C$. khmerensis sp. nov. and the C. tetracantha-group. Based on molecular and morphological evidence, we erect a new species group, $C$. khmerensis-group, to contain C. khmerensis sp. nov. and C.pfeifferi sp. nov. Divergence time estimates using MCMCTree shows that the root node of the $C$. khmerensis sp. nov. terminal is estimated to be of middle Miocene age at 15 million years old. The position of the C. khmerensis-group well supports the Oriental- to Australian-region dispersal history that has been proposed for the Australo-Asian Crematogaster clade.
\end{abstract}

Keywords. Biogeography, divergence time estimation, morphological assignment, nuclear genes, phylogenetic position.

Hosoishi S. \& Ogata K. 2017. Phylogenetic analysis and systematic position of two new species of the ant genus Crematogaster (Hymenoptera, Formicidae) from Southeast Asia. European Journal of Taxonomy 370: 1-17. https://doi.org/10.5852/ejt.2017.370

\section{Introduction}

Ants (Formicidae) are one of the most familiar insect groups and they play important ecological roles in the ecosystems they inhabit (Hölldobler \& Wilson 1990). They are abundant in terms of biomass, are distributed worldwide and form a diverse family, particularly in the tropics. Approximately $13000 \mathrm{ant}$ 
species have been described to date (Bolton 2014), and it is estimated that this number will increase to approximately 20000 species in future (Hölldobler \& Wilson 1990).

Ant taxonomy has been extensively investigated in recent years, with most taxonomic treatments typically presented as regional or systematic revisions. However, species with unique morphological characters are occasionally described separately from those comprehensive revisions. For example the Carebara phragmotica species clade and Tetraponera phragmotica have plug-shaped heads in the major worker caste (Ward 2006; Fischer et al. 2015); Crematogaster masukoi and C. myops have small compound eyes consisting of 5-6 ommatidia in the worker caste (Hosoishi et al. 2010). The possession of a phragmotic head suggests that the head is used to plug the nest entrance, and reduced compound eyes suggest a subterranean mode of life. Such derived states, as inferred by comparison with congenerics, are probably adaptations for particular life histories (e.g., predatory behavior, nesting habitat selection). Consequently, studies of distinct morphological characteristics are important contributions to ant taxonomy. While these distinct morphological forms (autapomorphies) can easily be distinguished from other more typical forms, and can therefore be described as new taxa, it can be difficult to determine their phylogenetic position. Thus, while uniqueness makes it easy to distinguish one taxon from others, elucidating the systematics of such taxa can be difficult.

Recent molecular analyses have revealed that some traditional taxa are not monophyletic e.g., (Cerapachyinae in Moreau et al. 2006, subgenera Paracrema and Physocrema in Blaimer 2012c, Aphaenogaster and Tetramorium by Ward et al. 2015). Indeed, since molecular data can resolve uncertainties in classification based on morphological data, an integrated approach that uses morphological data in conjunction with molecular phylogenetic analysis should be undertaken if fresh material is available.

The genus Crematogaster (Myrmicinae: Crematogastrini) is one of the hyperdiverse groups of ants, containing more than 400 species (Blaimer 2012b). The taxonomy has typically been examined as part of regional or systematic revisions (Longino 2003; Hosoishi \& Ogata 2009; Blaimer \& Fisher 2013), but some Crematogaster taxa with unique features have been recognized; for example, the C. borneensisgroup has reduced 10-segmented antennae and has mutualistic relationships with the ant-plant genus Macaranga (Feldhaar et al. 2016), several species in the subgenus Orthocrema have reduced compound eyes (Hosoishi et al. 2010), C. paradoxa and related species have distinctly elongated propodeal spines (Creighton 1945), C. reticulata has a strongly reticulated body surface (Hosoishi 2009), and the queen of C. cylindriceps has a phragmotic head (Wheeler 1927; Yamane et al. 2011). The systematic positions of these taxa are usually proposed based on molecular or morphological data (Blaimer 2012b; Hosoishi \& Ogata 2016), but the taxonomic affiliations are not always clear in some species.

In the course of a recent examination of Crematogaster specimens collected from Southeast Asia, we found two distinct species that appear to be new to science. None of the authors have ever seen any morphologically related species in a museum collection before. While the new species clearly belong to the subgenus Crematogaster sensu stricto (Blaimer 2012b), assignment to any of the species groups was not possible. The two species are considered to be distinct in that they both have vertically directed propodeal spines, which clearly distinguishes them from other Asian species of Crematogaster; however, their systematic positions are unknown.

The aims of this study were therefore to (1) clarify the phylogenetic position of these distinct Crematogaster ants using molecular phylogenetic analysis; (2) describe the two taxa as new species; (3) present the systematics of the two new species using morphological characters and molecular phylogenetic analysis. Morphological data in conjunction with molecular phylogenetic analysis will provide more comprehensive systematics of the two 'unique' species. 
HOSOISHI S. \& OGATA K., Phylogenetic position of two new Crematogaster ants

\section{Material and methods}

\section{Sources of material}

Type and non-type specimens were examined and/or deposited in the collections listed below. The species of Crematogaster from the Australian region are reviewed based on type and non-type specimen images available on AntWeb (https://www.antweb.org). Codes for public institutions generally follow those in Brandão (2000).

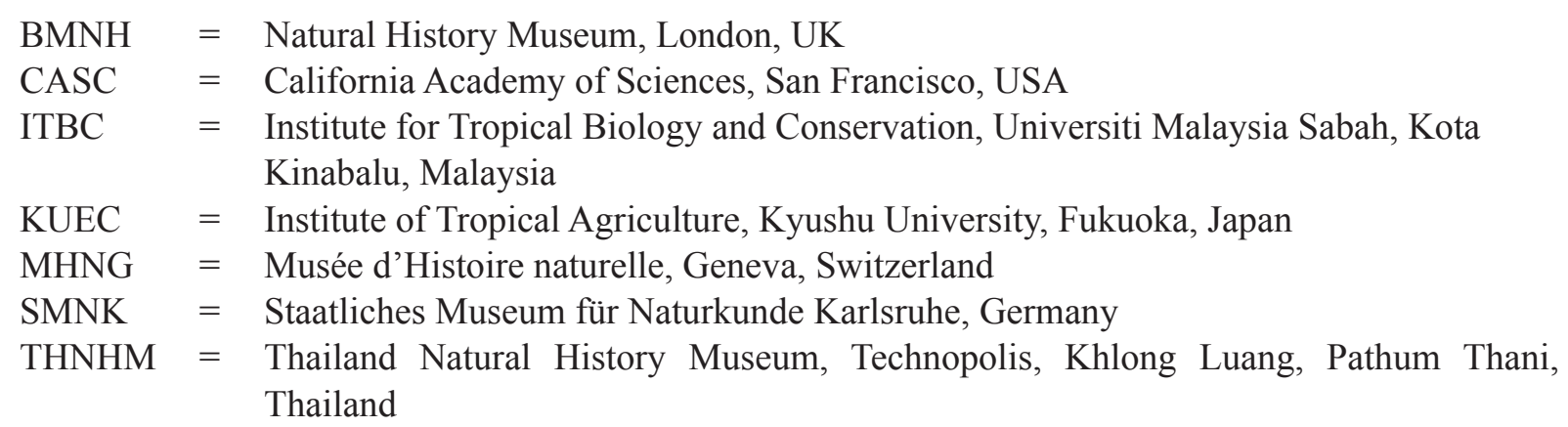

\section{Observation}

Most observations were made on a Leica M205C stereo microscope. Images were taken using a Canon EOS 50D with a Canon MP-E 65 mm 1-5 × Macro lens, then processed using Combine ZM.

\section{Measurements and indices}

Measurements were made under a Leica M205C stereo microscope using ocular micrometers. All measurements are expressed in millimeters, recorded to the second decimal place. The measurements for petiole and postpetiole follow Longino (2003).

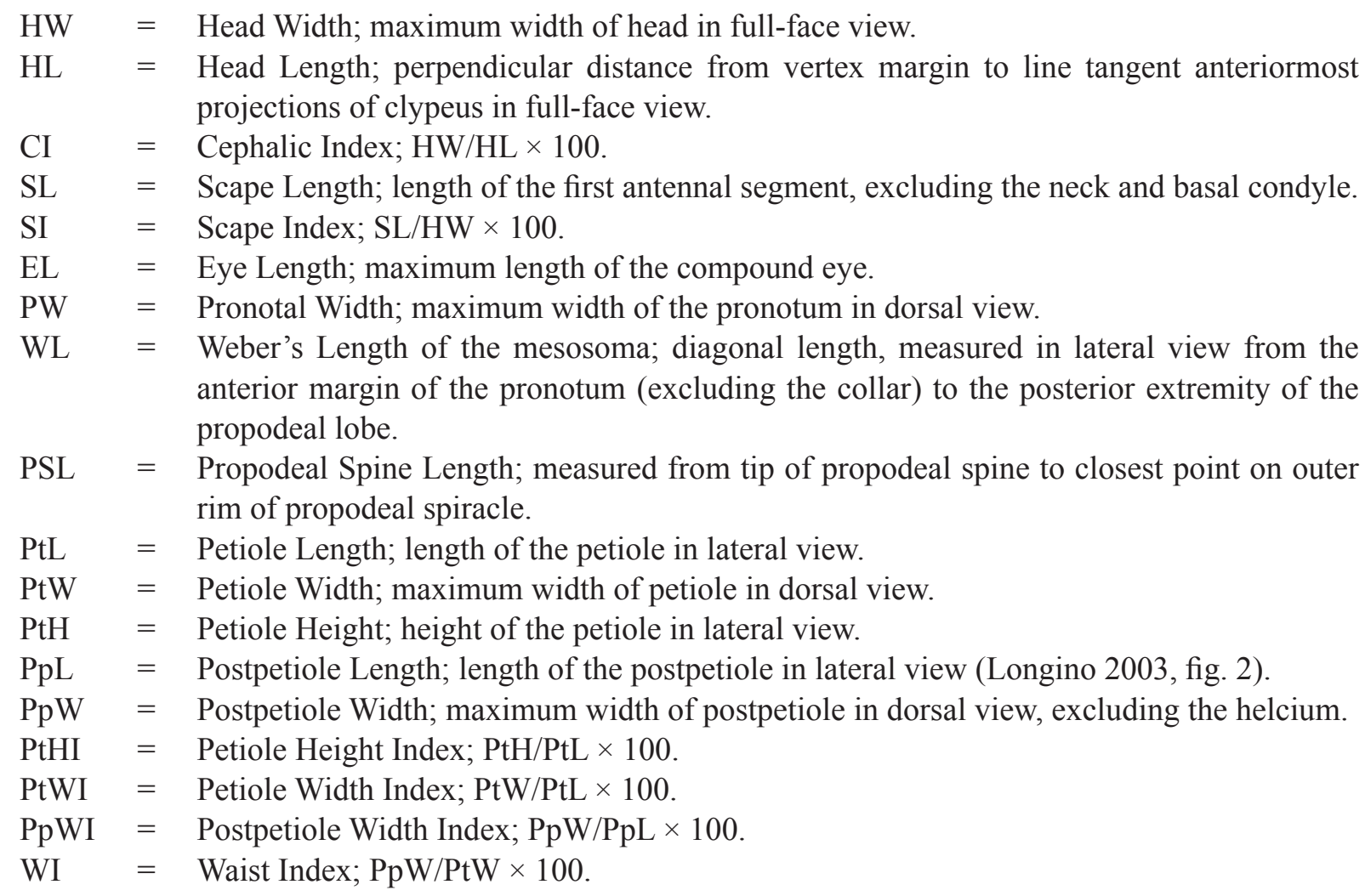




\section{Molecular data collection}

Genomic DNA was extracted using a DNeasy Blood \& Tissue kit (Qiagen, Maryland, USA). We sequenced fragments of five nuclear genes for one species, Crematogaster khmerensis sp. nov.: arginine kinase (ArgK, 402 bp), carbamoylphosphate synthase (CAD, 312 bp), long wavelength rhodopsin (LW $\mathrm{Rh}, 507 \mathrm{bp}$ ), DNA topoisomerase 1 (Top1, $795 \mathrm{bp}$ ) and wingless (Wg, $285 \mathrm{bp}$ ). The total number of base pairs for all genes was 2,301. Five new sequences were generated for this study, and the remainders were taken from Blaimer (2012c). Ninety taxa of Crematogaster (89 taxa of the subgenus Crematogaster analyzed in Blaimer (2012c) and C. khmerensis sp. nov.) were selected for molecular phylogenetic analysis. Primers, amplification and sequencing procedures followed Ward \& Downie (2005) and Blaimer (2012a). The sequence data for Crematogaster khmerensis sp. nov. were deposited at DNA Data Base of Japan (DDBJ) with accession numbers: LC171383 (ArgK); LC171382 (CAD); LC171384 (LWRh); LC171381 (Top1); LC171380 (Wg).

Reactions were carried out at $10 \mu \mathrm{l}$ volumes in a PCR Thermal Cycler MP (TaKaRa Bio Inc.) under the following conditions: first 40 cycles of $95^{\circ} \mathrm{C}$ for $30 \mathrm{~s}$, annealing at $50-58^{\circ} \mathrm{C}$ for $30 \mathrm{~s}$, and $72^{\circ} \mathrm{C}$ for $90 \mathrm{~s}$, then 1 cycle of $95^{\circ} \mathrm{C}$ for $1 \mathrm{~min}$, and finally $72^{\circ} \mathrm{C}$ for $3 \mathrm{~min}$. PCR products were visualized on a $1 \%$ agarose E-Gel 96-well system (Invitrogen), and then purified with 1.0 ul of ExoSAP-IT (GE Healthcare Life Sciences). All products were sequenced in both directions using BigDye Terminator v3.1 (Applied Biosystems) on an ABI 3100 Avant DNA Sequencer (Applied Biosystems) at the Faculty of Science, Kyushu University, Fukuoka. Contigs were made using Vector NTI Advance TM ver. 11 (Invitrogen Corp.) and subsequently aligned by eye. Sequence data were assembled and edited in the program Vector NTI Advance Tm ver. 11 (Invitrogen Corp.) and MEGA 5 (Tamura et al. 2011).

\section{Phylogenetic inference}

The dataset was analyzed using maximum parsimony (MP), maximum likelihood (ML), and Bayesian inference (BI) to explore the strength of the phylogenetic signal under different optimality criteria.

The MP analysis was performed using TNT 1.1 program (Goloboff et al. 2008) with outgroup rooting, default consensus options, Tree Bisection and Reconstruction (TBR) branch swapping, and the default 'traditional search' mode. The tree search employed a parsimony ratchet with 10000 interactions per run. Parsimony analyses were completed under conditions of equal weighting. Tree analyses were performed with WinClada version 1.00.08 software (Nixon 2002), and consensus cladograms generated from equally parsimonious trees were generated using the same program. Trees were rooted by the outgroup taxon Crematogaster osakensis belonging to the subgenus Orthocrema.

For ML and BI analyses, we first used PartitionFinder v.1.1.1 (Lanfear et al. 2012) to determine the bestfitting partition and substitution models for the phylogenetic analysis. For ML, under 'models = all', 'model selection = bic', and 'search = greedy', PartitionFinder identified five partitions (Table 1), which were employed in the ML analysis. Tree searches were conducted in GARLI v.2.0 (Zwickl 2006), with the following modification from default setting: genthreshfortopoterm $=100000$, after Ward \& Fisher (2016). Bootstrap values were calculated in PAUP*4.0b10 (Swofford 2002) using 100 bootstrap replicates from trees built in GARLI.

The BI analysis was performed using MrBayes v.3.1.2 (Ronquist \& Huelsenbeck 2003). For the BI, model selection was limited to those that could be implemented in MrBayes, using the function 'model $=$ mrbayes' in PartitionFinder. The best-fitting partition and substitution models chosen for BI analysis were shown in Table 1. We ran two independent runs with four chains each for 10 million generations, sampling every 1000 generations. All runs reached stationarity, as judged by the average standard deviation of split frequencies (ASDSF) approaching 0.01. The program Tracer v.1.6 (Rambaut et al. 2014) was used to evaluate convergence to the stationary distribution and effective sample size (ESS). 
Table 1. Partitions and models identified by PartitionFinder and used in the maximum likelihood (ML) and Bayesian (BI) analyses.

\begin{tabular}{lcc}
\hline Blocks & Partition & Model \\
\hline \multicolumn{1}{c}{ ML } & & \\
ArgK_pos1, CAD_pos1, LWRh_pos2 & $\mathrm{p} 1$ & $\mathrm{~K} 80+\mathrm{I}$ \\
ArgK_pos2, CAD_pos2, LWRh_pos1, Top1_pos1, Top1_pos2 & $\mathrm{p} 2$ & $\mathrm{HKY}+\mathrm{I}+\mathrm{G}$ \\
ArgK_pos3, LWRh_pos3, Wg_pos3 & $\mathrm{p} 3$ & $\mathrm{~K} 80+\mathrm{G}$ \\
CAD_pos3, Top1_pos3 & $\mathrm{p} 4$ & $\mathrm{TrNef}+\mathrm{G}$ \\
Wg_pos1, Wg_pos2 & $\mathrm{p} 5$ & $\mathrm{~K} 80+\mathrm{I}$ \\
\multicolumn{1}{c}{ BI } & & \\
ArgK_pos1, CAD_pos1, LWRh_pos2, Wg_pos1 & $\mathrm{p} 1$ & $\mathrm{~K} 80+\mathrm{I}+\mathrm{G}$ \\
ArgK_pos2, CAD_pos2, LWRh_pos1, Top1_pos1, Top1_pos2, Wg_pos2 & $\mathrm{p} 2$ & $\mathrm{HKY}+\mathrm{I}+\mathrm{G}$ \\
ArgK_pos3, CAD_pos3, LWRh_pos3, Top1_pos3, Wg_pos3 & p3 & $\mathrm{K} 80+\mathrm{G}$ \\
\hline
\end{tabular}

The likelihood values converged to relative stationarity after $\sim 1$ million generations. ESS values for all parameters were well above 2000, providing evidence that convergence had been reached. Approximately $25 \%$ of samples were discarded as burn-in before parameters and trees were summarized. Posterior probabilities are given as statistical branch support.

\title{
Divergence time estimation
}

The concatenated five gene sequences from 24 myrmicine taxa (17 taxa of the Australo-Asian Crematogaster clade, C. longispina, C. torosa, Aphaenogaster occidentalis, Leptothorax cf. muscorum, Stenamma dyscheres and Temnothorax rugatulus analyzed in Blaimer (2012c), and Crematogaster khmerensis sp. nov.) and the monophyly-constrained topology which Blaimer (2012c) inferred were used for molecular dating analyses. Four fossil calibrations were incorporated following Blaimer (2012c). Divergence times were estimated using the Bayesian method implemented in MCMCTree of PAML4.7 (Yang 2007). Using the approximate likelihood calculation method, the gradient $g$ and Hessian $H$ with BASEML using the GTR $+G$ substitution model were calculated (dos Reis \& Yang 2011). The independent rate model for the molecular clock and the GTR + G model for nucleotide substitutions were set in the memctree.ctl control file, with the following modification from default setting: substitution rate per time unit $=0.106023$; rgene_gamma $=110$; sigma2_gamma $=14.5$.

\section{Results}

\author{
Class Hexapoda Blainville, 1816 \\ Order Hymenoptera Linnaeus, 1758 \\ Suborder Apocrita Latreille, 1810 \\ Infraorder Aculeata Latreille, 1802 \\ Superfamily Vespoidea Latreille, 1802 \\ Family Formicidae Latreille, 1809 \\ Subfamily Myrmicinae Lepeletier de Saint-Fargeau, 1835
}

Genus Crematogaster Lund, 1831

\section{Phylogenetic position and divergence time estimation}

The five nuclear gene sequences consisted of $2301 \mathrm{bp}$ and contained 652 variable characters (VC) and 420 parsimony informative characters (PIC) (Table 2). The MP and ML analyses resulted in similar 
Table 2. Data on number of bases, number of variable characters (VC) and number of parsimony informative characters (PIC).

\begin{tabular}{lccc}
\hline Gene & No. bases & No. VC & No. PIC \\
\hline ArgK & 402 & 125 & 74 \\
CAD & 312 & 100 & 67 \\
LWRh & 507 & 140 & 93 \\
Top1 & 795 & 215 & 142 \\
Wg & 285 & 72 & 44 \\
Total & 2301 & 652 & 420 \\
\hline
\end{tabular}

topologies for the position of C. khmerensis sp. nov., but the BI analysis differed in topology from the MP and ML analyses. As our results from the BI analysis had similar results to the tree inferred by Blaimer (2012c), we use the BI tree to illustrate all our results (Fig. 1).

In MP analysis, the concatenated five-gene dataset yielded 1800 equally parsimonious trees (length $=1407$, consistency index $=0.48$, retention index $=0.77$ ), of which the strict consensus tree is well resolved. The MP analysis recovered that $C$. khmerensis sp. nov. was nested within node A with high bootstrap support (100\%) (Fig. 2). Further splitting of the node resulted in a trichotomy having branches with $C$. khmerensis sp. nov., C. borneensis-group and node $\mathrm{C}$.

The ML analysis recovered that $C$. khmerensis sp. nov. was nested within node A with high bootstrap support (100\%) (Fig. 2). Similarly the node displayed a trichotomy among C. khmerensis sp. nov., C. borneensis-group and node C.

The BI recovered that $C$. khmerensis sp. nov. was nested within node A (Fig. 2). Despite the relatively low level of support ( 0.88 posterior probability), C. khmerensis sp. nov. at node B was a sister to node $\mathrm{C}$ (Fig. 2).

Estimations of divergence time showed that the common ancestor of C. khmerensis sp. nov. and clade $\mathrm{C}$ began to diverge approximately 15 million years ago (Fig. 3).

\section{Diagnosis of the Crematogaster khmerensis-group}

the Crematogaster khmerensis-group is easily distinguished from other Asian species of Crematogaster by the vertically directed propodeal spines and large propodeal spiracles.

Species included in the Crematogaster khmerensis-group:

C. khmerensis Hosoishi \& Ogata sp. nov.

C. pfeifferi Hosoishi \& Ogata sp. nov.

\section{Key to species based on the worker caste}

1. Propodeal spiracles large and touching metapleural gland bulla. Petiole scoop shaped, broader anteriorly. Subpetiolar process undeveloped (Cambodia) C. khmerensis sp. nov.

- Propodeal spiracles large and apart from metapleural gland bulla. Petiole elliptical with convex sides. Subpetiolar process developed acutely (Borneo) C. pfeifferi sp. nov. 


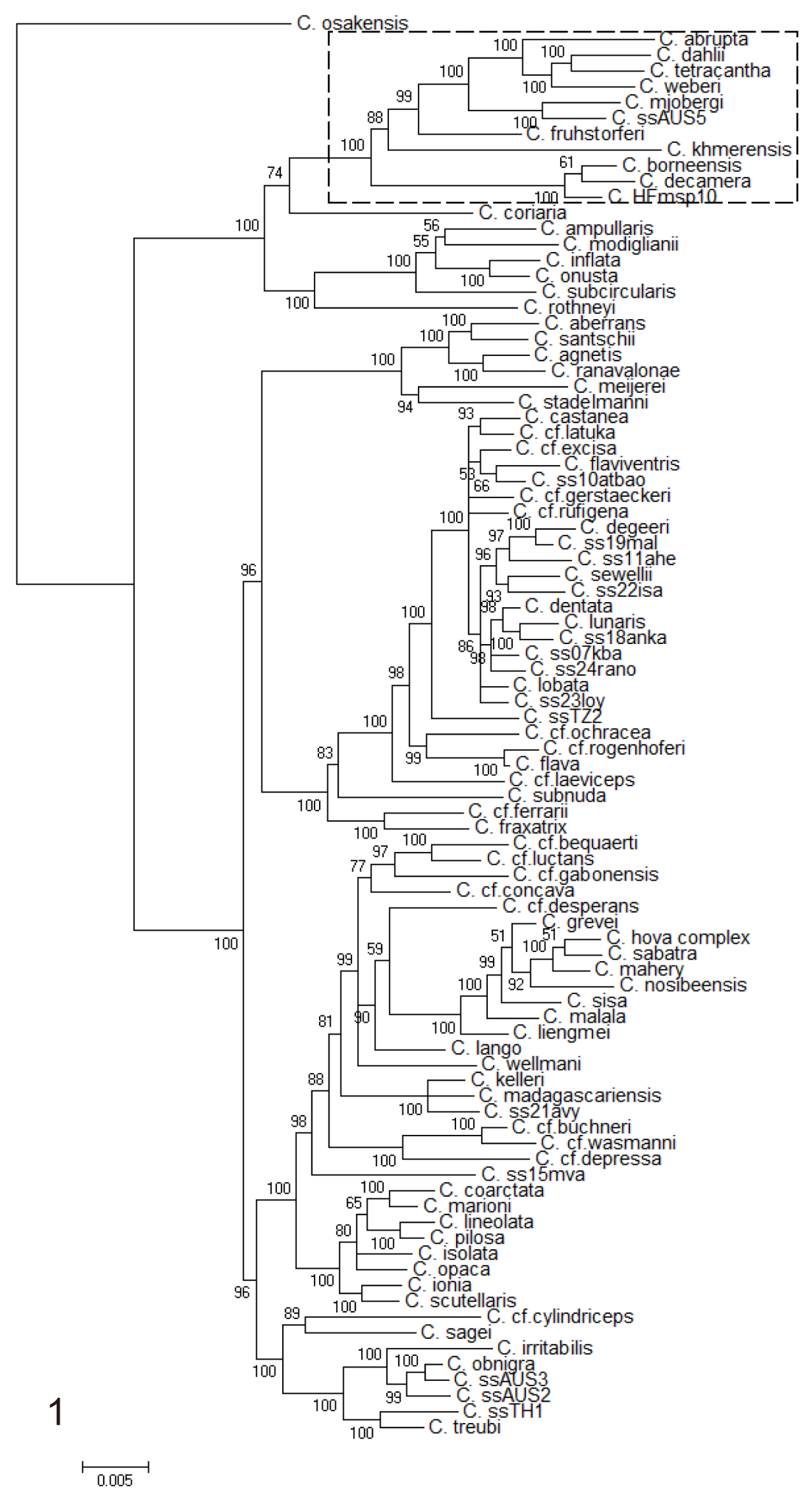

Fig. 1. Bayesian majority rule consensus tree reconstructed for 90 taxa using five genes (ArgK, CAD, LWRh, Top1, Wg) in a MrBayes analysis. Above node numbers indicate posterior probability. Data were partitioned by PartitionFinder v.1.1.1 and analyzed using a best fit model for each gene and codon position, with 10 million generations and a burn-in of $25 \%$. Area enclosed by dashed lines is enlarged on Fig. 2. 


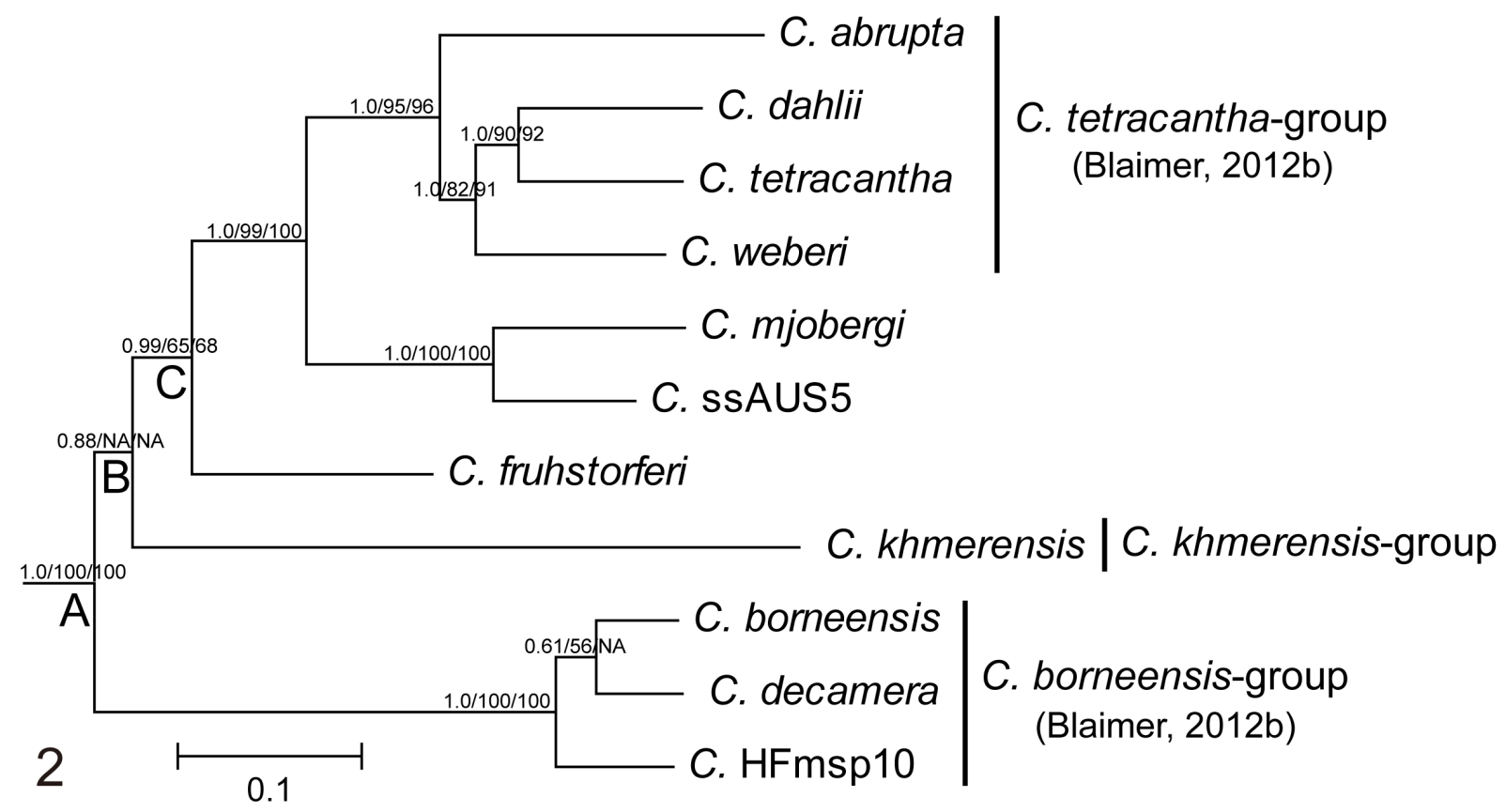

Fig. 2. Bayesian majority rule consensus tree reconstructed for 90 taxa using five genes (ArgK, CAD, LWRh, Top1, Wg) in a MrBayes analysis. Most of the outgroups are not shown. Above node numbers indicate posterior probability, bootstrap value for MP, and bootstrap value for ML. Data were partitioned by PartitionFinder v.1.1.1 and analyzed using a best fit model for each gene and codon position, with 10 million generations and a burn-in of $25 \%$.

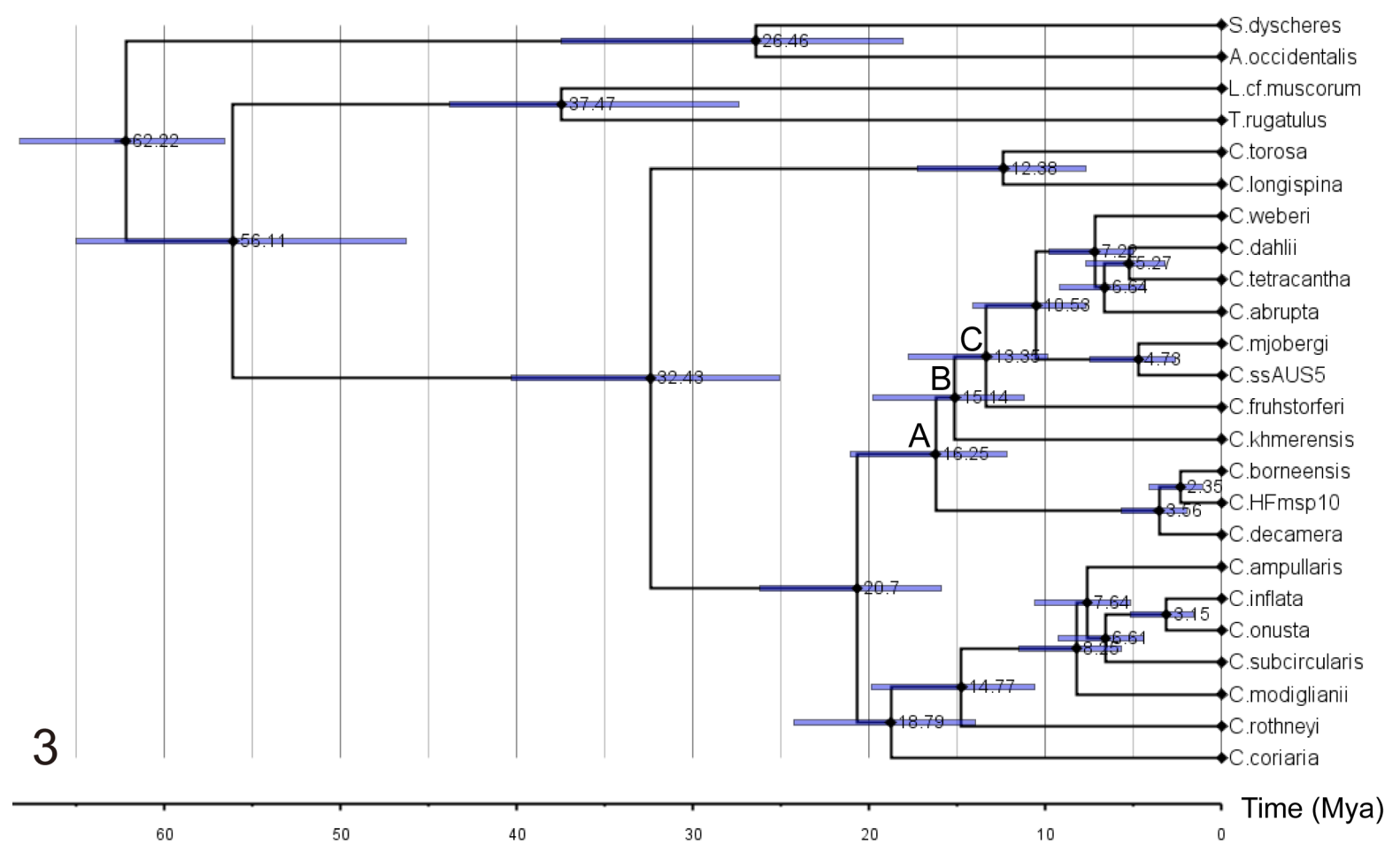

Fig. 3. Posterior estimates of divergence time of 24 taxa on the phylogenetic tree. Blue bars depict the $95 \%$ highest posterior density (HPD). Estimations were performed with MCMCTree using the independent rate model. 
HOSOISHI S. \& OGATA K., Phylogenetic position of two new Crematogaster ants

\section{Crematogaster khmerensis sp. nov. urn:1sid:zoobank.org:act:D2CC1731-9989-4708-9513-36E1458CE012}

Figs 4A-D

\section{Diagnosis}

Crematogaster khmerensis sp. nov. belongs to the subgenus Crematogaster sensu stricto (Blaimer 2012b). This small-sized species of Crematogaster ants (HW 0.6-0.66; WL 0.63-0.69) is similar to C. pfeifferi sp. nov., but can be distinguished by the propodeal spiracles touching metapleural gland bulla, short propodeal spines (PSL 0.08-0.09), petiole broader anteriorly than posteriorly and undeveloped subpetiolar process.

\section{Etymology}

The specific name refers to the former kingdom name of Cambodia, the Khmer Empire.

\section{Type specimens}

\section{Holotype}

CAMBODIA: worker, Kampong Thom Province, 24 Nov. 2010, S. Hosoishi leg., (TUS arboreal SF3-1) (KUMANT040: deposited at THNHM).

\section{Paratypes}

CAMBODIA: 3 workers, same locality data as for holotype (TUS arboreal SF3-3, TUS arboreal SF3-6) (KUMANT041: deposited at BMNH; KUMANT042: deposited at CASC; KUMANT043: deposited at KUEC).

\section{Measurements and indices}

HW 0.60-0.66; HL 0.60-0.67; CI 97-102; SL 0.43-0.50; SI 69-76; EL 0.14-0.15; PW 0.35-0.40; WL 0.63-0.69; PSL 0.08-0.09; PtL 0.22-0.23; PtW 0.20-0.25; PtH 0.12-0.14; PpL 0.12-0.14; PpW 0.20-0.23; PtHI 52-64; PtWI 87-114; PpWI 154-167; WI 92-100 (holotype and three paratype workers measured).

\section{Description}

\section{Worker}

Workers presumably monomorphic.

Head subquadrate in full-face view, with rounded posterior corners and subparallel sides. Occipital carinae developed. Mandible with four teeth, apical tooth large. Anterior margin of clypeus convex; anterolateral margins of clypeus protruded anteriorly; posterior margin of clypeus rounded between frontal lobes. Frontal carinae almost parallel. Antennae 11-segmented; antennal club 3-segmented. Scape reaching posterior corner of head. Basal flagellar segment (antennal segment III) as broad as long. Compound eyes slightly projecting beyond lateral margins of head in full face view.

Pronotal shoulders angulate, but without distinct rugulae laterally. Mesonotal dorsum convex in lateral view. Pronotum and mesonotum not forming same dorsal outline in lateral view. Mesothoracic spiracle forms large pit concealed by posterior pronotal lobe. Metapleural gland opening slit-shaped. Propodeal spiracle large and circular, situated at posterolateral corners, touching metapleural gland bulla. Metanotal groove straight in dorsal view, deep and forming concave region between mesonotum and propodeum. In dorsal view, feeble longitudinal rugulae connecting between mesonotum and propodeum; the boundary distinct. Propodeal spines developed and directed vertically in lateral view. 

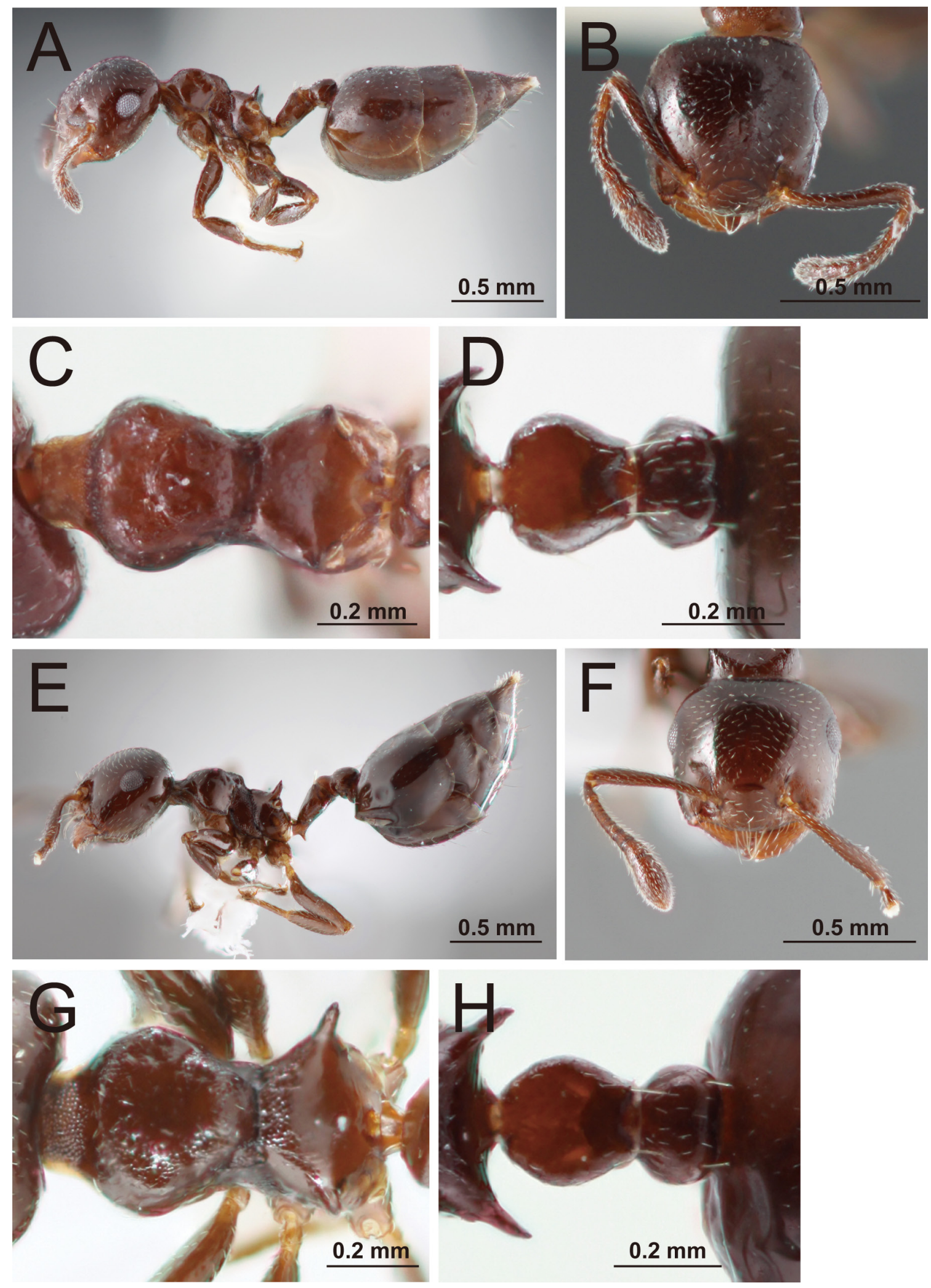

Fig. 4. A-D. Crematogaster khmerensis sp. nov., worker. A. Body in lateral view. B. Full-face view of head. C. Dorsal view of mesosoma. D. Petiole and postpetiole in dorsal view. $-\mathbf{E}-\mathbf{H}$. - Crematogaster pfeifferi sp. nov., worker. E. Body in lateral view. F. Full-face view of head. G. Dorsal view of mesosoma. H. Petiole and postpetiole in dorsal view. 
HOSOISHI S. \& OGATA K., Phylogenetic position of two new Crematogaster ants

Petiole scoop shaped, but flattened broader anteriorly, longer than broad; spiracle situated anteriorly midway between dorsal and ventral margin of petiole in lateral view, directed laterally. Subpetiolar process developed as a short lamellate denticle. Postpetiole without longitudinal median sulcus, but bilobed behind; spiracle situated anteriorly on lateral surface.

Dorsal surface of head mostly smooth or weakly shagreened. Clypeus mostly smooth and shining. Pronotal collar areolately sculptured. Promesonotum weakly punctate. Lateral surface of pronotum smooth and shining. Mesopleuron mostly smooth and shining, but sculptured on surrounding area. Anterodorsal surface of propodeum weakly punctate; posteior half smooth and shining. Lateral surface of propodeum smooth and shining. Dorsal and lateral surfaces of petiole smooth and shining. Dorsal and lateral surfaces of postpetiole smooth and shining.

Standing pilosity sparse. Dorsal face of head with appressed setae; one pair of erect setae on frontal lobes. Clypeus with one pair of erect setae. Anterior clypeal margin with two pairs of long setae mixed with short setae laterally. Scape with decumbent setae. Mesontum with appressed setae sparsely. Petiole with one pair of suberect setae posteriorly. Postpetiole with one pair of suberect setae posteriorly. Fourth abdominal tergite with short appressed setae sparsely.

Body color brown

\section{Queen and male}

Queens and males of this species are unknown.

\section{Distribution}

This species is known only from the type locality in Cambodia (Fig. 5).

Crematogaster pfeifferi Hosoishi \& Ogata sp. nov. urn:1sid:zoobank.org:act:BE4FEAC9-A8EE-4C65-B00D-B62263746F70

Figs 4E-H

\section{Diagnosis}

Crematogaster pfeifferi sp. nov. belongs to the subgenus Crematogaster sensu stricto (Blaimer 2012b). This species is small-sized Crematogaster ants (HW 0.65-0.68; WL 0.69-0.7). This species is similar to $C$. khmerensis sp. nov., but can be distinguished by the propodeal spiracles apart from metapleural gland bulla, long propodeal spines (PSL 0.11-0.12), elliptical petiole and acutely developed subpetiolar process.

\section{Etymology}

The specific name is dedicated to Dr. Martin Pfeiffer, who collected the type material.

\section{Type specimens}

\section{Holotype}

MALAYSIA: worker, Borneo, Golden Hope Table, $4^{\circ} 23$ N, $117^{\circ} 51$ E, xa178 611, 8 Oct. 2004, M. Pfeiffer leg., (KUMANT044: deposited at ITBC).

\section{Paratypes}

MALAYSIA: 3 workers, same data as for holotype, xa160 610 (KUMANT045: deposited at BMNH; KUMANT046: deposited at KUEC; KUMANT047: deposited at SMNK). 


\section{Measurements and indices}

HW 0.65-0.68; HL 0.62-0.64; CI 105-106; SL 0.49-0.51; SI 75-76; EL 0.13-0.14; PW 0.37-0.39; WL 0.69-0.70; PSL 0.11-0.12; PtL 0.24-0.25; PtW 0.22-0.24; PtH 0.13-0.15; PpL 0.14-0.15; PpW 0.22-0.24; PtHI 52-63; PtWI 92-96; PpWI 157-164; WI 92-100 (holotype and three paratype workers measured).

\section{Description}

\section{Worker}

Workers presumably monomorphic.

Head subquadrate in full-face view, with rounded posterior corners and subparallel sides. Occipital carinae developed. Mandible with four teeth, apical tooth large. Anterior margin of clypeus convex; anterolateral margins of clypeus protruded anteriorly; posterior margin of clypeus rounded between frontal lobes. Frontal carinae almost parallel. Antennae 11-segmented; antennal club 3-segmented.

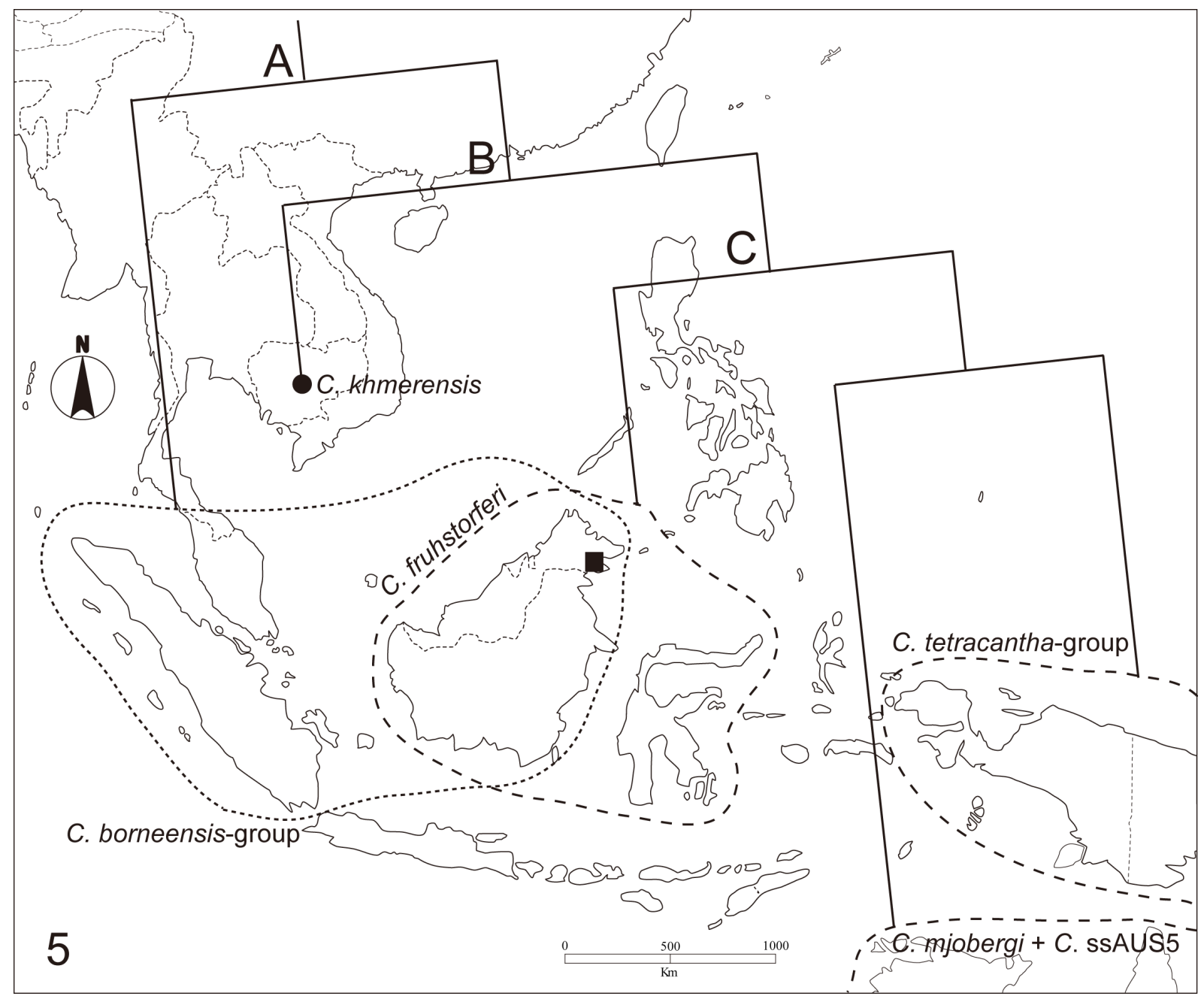

Fig. 5. Phylogeny and distribution of the Crematogaster borneensis-group, C. khmerensisi sp. nov., C. fruhstorferi, C. ssAUS5, C. mjobergi and the C. tetracantha-group. Closed circle indicates C. khmerensis sp. nov., closed square indicates C. pfeifferi sp. nov. It is noted that C.pfeifferi sp. nov. is not represented in the phylogeny. 
Scape reaching posterior corner of head. Basal flagellar segment (antennal segment III) slightly longer than broad. Compound eyes slightly projecting beyond lateral margins of head in full-face view.

Pronotal shoulders angulate, but without distinct rugulae laterally. Mesonotal dorsum convex in lateral view. Pronotum and mesonotum not forming same dorsal outline in lateral view. Mesothoracic spiracle forms large pit concealed by posterior pronotal lobe. Metapleural gland opening slit-shaped. Propodeal spiracle large and circular, situated at posterolateral corners, apart from metapleural gland bulla. Metanotal groove straight in dorsal view, deep and forming concave region between mesonotum and propodeum. In dorsal view, feeble longitudinal rugulae connecting between mesonotum and propodeum; the boundary distinct. Propodeal spines developed and directed vertically in lateral view.

Petiole elliptical with convex sides, longer than broad; spiracle situated anteriorly midway between dorsal and ventral margin of petiole in lateral view, directed laterally. Subpetiolar process developed acutely. Postpetiole without longitudinal median sulcus, but bilobed behind; spiracle situated anteriorly on lateral surface.

Dorsal surface of head mostly smooth or weakly shagreened. Clypeus mostly smooth and shining. Pronotal collar areolately sculptured. Promesonotum weakly punctate. Lateral surface of pronotum smooth and shining. Mesopleuron mostly smooth and shining, but sculptured on surrounding area. Anterodorsal surface of propodeum weakly punctate; posterior half smooth and shining. Lateral surface of propodeum smooth and shining. Dorsal and lateral surfaces of petiole smooth and shining. Dorsal and lateral surfaces of postpetiole smooth and shining.

Standing pilosity sparse. Dorsal face of head with decumbent setae; one pair of erect setae on frontal lobes. Clypeus with one pair of erect setae. Anterior clypeal margin with two to three pairs of long setae mixed with short setae laterally. Scape with appressed setae. Mesonotum with appressed setae sparsely. Petiole with one pair of suberect setae posteriorly. Postpetiole with one pair of suberect setae posteriorly. Fourth abdominal tergite with short appressed setae sparsely.

Body color brown.

\section{Queen and male}

Queens and males of this species are unknown.

\section{Distribution}

This species is known only from the type locality in Malaysia (Borneo) (Fig. 5).

\section{Discussion}

\section{Phylogenetic position of $C$. khmerensis sp. nov.}

The MP and ML analyses consistently placed C. khmerensis sp. nov. nested within node A, and forming an unresolved trichotomy with C. borneensis-group and node C (Fig. 2). The reason for this is not clear, but might be due to the large amount of missing data. The BI analysis recovered C. khmerensis sp. nov. nested within node $\mathrm{A}$, and sister to node $\mathrm{C}$, albeit with a low support value. The node $\mathrm{A}$ corresponds to node 231 (Blaimer 2012c, fig. 3) of the Australo-Asian Crematogaster clade (Blaimer 2012c, fig. 2, III), the node C corresponds to node 230 (Blaimer 2012c, fig. 3).

In this study, the consensus tree obtained by the BI analysis was used to infer the phylogenetic relationships as our results (Fig. 1) from the BI analysis had similar results to the tree inferred by Blaimer (2012c). The position of C. khmerensis sp. nov. is recovered as a sister to clade C, which 
comprises of $C$. fruhstorferi $+C$. ss_AUS5 $+C$. mjobergi + the $C$. tetracantha-group, with the basal C. borneensis-group (Fig. 2).

\section{Morphological assignment of species}

While we did not find conclusive evidence of synapomorphies uniting C. khmerensis sp. nov. and clade $\mathrm{C}$ in this study, several potential characters are suggested below. Crematogaster fruhstorferi has short, stout propodeal spines and large propodeal spiracles. The propodeal spines of $C$. fruhstorferi are diverged posteriorly, but not directed vertically as in C. khmerensis sp. nov. The propodeal spiracles of $C$. fruhstorferi are as large as the base of the propodeal spines, but not 2-3 times as large as in $C$. khmerensis sp. nov. These morphological data suggest affinity, but are inconclusive. The C. tetracantha-group has laterally-developed pronotal shoulders (Blaimer 2012b), especially C. dahlii and $C$. tetracantha, which have pronotal shoulders distinctly developed as spines. The presence of laterally-developed pronotal shoulders suggests a close affiliation between C. khmerensis sp. nov. and the members of the C. tetracantha-group, even though C. fruhstorferi, C. mjobergi and C. ssAUS5 do not have developed pronotal shoulders. The phylogenetic relationship inferred by molecular analysis indicates that laterally-developed pronotal shoulders evolved independently and in two steps, i.e., once in C. khmerensis sp. nov. and also at base of the C. tetracantha-group, or it is also parsimonious that the shoulders were gained in the ancestor of the clade B then lost in the C. mjobergi and C. ssAUS5 clade.

Based on molecular and morphological evidence, we treat $C$. khmerensis sp. nov. as its own species group, the Crematogaster khmerensis-group. In this study, no obvious synapomorphies were identified among C. khmerensis sp. nov. and clade C. Since the existence of undescribed and/or unanalyzed species may decrease the resolution of higher taxonomic levels, the inclusion of more species and morphological characters in both the queen and male castes is considered necessary to corroborate its validity. Further studies should therefore be conducted on closely related taxa to more accurately clarify the position of the C. khmerensis-group.

Although we do not have fresh material of C. pfeifferi sp. nov. for molecular phylogenetic analysis, the species is considered to be most closely related to C. khmerensis sp. nov. and is therefore assigned as a sister species.

\section{Dispersal history of the Australo-Asian Crematogaster clade}

Blaimer (2012c, fig. 3c) proposed that the Australo-Asian Crematogaster clade evolved in Southeast Asia before colonizing the adjacent Australasian region. Clade C, comprising C. fruhstorferi $+C$. ss AUS5 + C. mjobergi + the C. tetracantha-group, is mostly distributed eastward of Wallace's line, although C. fruhstorferi is also known from Borneo (Blaimer 2012c, CASENT0193728 specimen). The position of C. khmerensis sp. nov., as sister to C. fruhstorferi and the Australasian clade, supports Blaimer's hypothesis of dispersal from the Oriental to the Australian regions (Figs 2, 5), suggesting that sequential dispersal events occurred in different lineages and that they were widespread.

The divergence time estimation and phylogenetic analysis suggest that the most recent common ancestor of C. khmerensis sp. nov. and clade $\mathrm{C}$ was inferred to be 15 million years old (Middle Miocene), when the Sundaic region was connected to the extended Indochinese Peninsula (Lohman et al. 2011, fig. 2d). The common ancestor of the C. khmerensis-group was likely distributed over parts of the Sundaic region during periods of low sea level, which would have allowed it to disperse into Indochina and Sundaland before diverging into different taxa as a result of vicariance. The remaining taxa may have dispersed to Sulawesi and Australasian regions east of Wallace's line and diverged. Our divergence time estimations were approximately 5 million years younger than those attained by Blaimer (2012c). While her analysis estimated the node 245 (Blaimer 2012c, fig. 3) at ca 27 Mya, our analysis estimated the same node at ca 
HOSOISHI S. \& OGATA K., Phylogenetic position of two new Crematogaster ants

21 Mya (Fig. 3). This incongruence might be due to the analysis with a subset of her taxon matrix and different method.

Despite extensive field surveys by myrmecologists on the Indochinese Peninsula and Borneo, only two series of the $C$. khmerensis-group have ever been recorded from Cambodia and Borneo. The members of the C. khmerensis-group are therefore considered to be rare and relatively old taxa with restricted distribution ranges.

\section{Acknowledgements}

We would like to thank Mr Phourin Chhang and Mr. Vanna Samreth (Forestry Administration, Phnom Penh, Cambodia), Dr Tsuyoshi Kajisa (Kagoshima University) and Dr Nobuya Mizoue (Faculty of Agriculture, Kyushu University) and Dr Tetsukazu Yahara (Faculty of Science, Kyushu University) for helping our field surveys in this study. Important material was received from Dr. Martin Pfeiffer. We would like to thank the ANeT members for encouragement. We thank Francisco Hita Garcia and one anonymous reviewer for useful comments and suggestions. Thanks are also due to Mark Lorenz (Forte Inc.) for improving the English. This work was supported in part by JSPS KAKENHI (Grant-in-Aid for Scientific Research (C)) Grant Number 26440221, JSPS KAKENHI (Grant-in-Aid for Scientific Research (B)) Grant Number 26304014 and Global COE Program (Center of Excellence for Asian Conservation Ecology as a basis of Human-Nature Mutualism), MEXT, Japan.

\section{References}

AntWeb. Available from https://www.antweb.org [accessed Mar. 2016].

Blaimer B.B. 2012a. Untangling complex morphological variation: taxonomic revision of the subgenus Crematogaster (Oxygyne) in Madagascar, with insight into the evolution and biogeography of this enigmatic ant clade (Hymenoptera: Formicidae). Systematic Entomology 37 (2): 240-260. https://doi.org/10.1111/j.1365-3113.2011.00609.x

Blaimer B.B. 2012b. A subgeneric revision of Crematogaster and discussion of regional species-groups (Hymenoptera: Formicidae). Zootaxa 3482: 47-67.

Blaimer B.B. 2012c. Acrobat ants go global-Origin, evolution and systematics of the genus Crematogaster (Hymenoptera: Formicidae). Molecular Phylogenetics and Evolution 65: 421-436. https://doi.org/10.1016/j.ympev.2012.06.028

Blaimer B.B. \& Fisher B.L. 2013. Taxonomy of the Crematogaster degeeri-species-assemblage in the Malagasy region (Hymenoptera: Formicidae). European Journal of Taxonomy 51: 1-64. https://doi.org/10.5852/ejt.2013.51

Bolton B. 2014. An Online Catalog of the Ants of the World. Available from http://antcat.org [accessed Jan. 2016].

Brandão C.R.F. 2000. Major regional and type collections of ants (Formicidae) of the World and sources for the identification of ant species. In: Agosti D., Majer J.D., Alonso L.E. \& Schultz T.R. (eds) Ants: Standard methods for measuring and monitoring biodiversity: 172-185. Smithsonian Institution Press, Washington \& London.

Creighton W.S. 1945. Observations on the subgenus Rhachiocrema with the description of a new species from Borneo. Psyche 52: 109-118. https://doi.org/10.1155/1945/35419

Feldhaar H., Maschiwitz U. \& Fiala B. 2016. Taxonomic revision of the obligate plant-ants of the genus Crematogaster Lund (Hymenoptera: Formicidae: Myrmicinae), associated with Macaranga 
Thouars (Euphorbiaceae) on Borneo and the Malay Peninsula. Sociobiology 63: 651-681. https://doi.org/10.13102/sociobiology.v63i1.949

Fischer G., Azorsa F., Hita Garcia F., Mikheyev A.S. \& Economo E.P. 2015. Two new phragmotic ant species from Africa: morphology and next-generation sequencing solve a caste association problem in the genus Carebara Westwood. ZooKeys 525: 77-105. https://doi.org/10.3897/zookeys.525.6057

Goloboff P., Farris J. \& Nixon K. 2008. TNT, a free program for phylogenetic analysis. Cladistics 24: 774-786. https://doi.org/10.1111/j.1096-0031.2008.00217.x

Hölldobler B. \& Wilson E.O. 1990. The Ants. Harvard University Press, Cambridge.

Hosoishi S. 2009. A new species from Crematogaster the subgenus Orthocrema in Asia (Hymenoptera: Formicidae). Japanese Journal of Systematic Entomology 15: 259-262.

Hosoishi S. \& Ogata K. 2009. A taxonomic revision of the Asian endemic subgenus Physocrema of the genus Crematogaster (Hymenoptera: Formicidae). Zootaxa 2062: 15-36.

Hosoishi S., Yamane Sk. \& Ogata K. 2010. Subterranean species of the ant genus Crematogaster in Asia (Hymenoptera: Formicidae). Entomological Science 13: 345-350. https://doi.org/10.1111/j.1479-8298.2010.00390.x

Hosoishi S. \& Ogata K. 2016 Systematics and biogeography of the ant genus Crematogaster Lund subgenus Orthocrema Santschi in Asia (Hymenoptera: Formicidae). Zoological Journal of the Linnean Society 176: 547-606. https://doi.org/10.1111/zoj.12330

Lanfear R., Calcott B., Ho S.Y.W. \& Guindon S. 2012. Partition Finder: combined selection of partitioning schemes and substitution models for phylogenetic analysis. Molecular Biology and Evolution 29: 16951701. https://doi.org/10.1093/molbev/mss020

Lohman D.J., de Bruyn M., Page T., Rintelen K. von, Hall R., Ng P.K.L., Shin H.-T., Carvalho G.R. \& Rintelen T. von. 2011. Biogeography of the Indo-Australian Archipelago. Annual Review of Ecology, Evolution, and Systematics 42: 205-226. https://doi.org/10.1146/annurev-ecolsys-102710-145001

Longino J.T. 2003. The Crematogaster (Hymenoptera, Formicidae, Myrmicinae) of Costa Rica. Zootaxa 151: 1-150. https://doi.org/10.11646/zootaxa.151.1.1

Moreau C.S., Bell C.D., Vila R., Archibald S.B. \& Pierce N.E. 2006. Phylogeny of the ants: diversification in the age of angiosperms. Science 312: 101-104. https://doi.org/10.1126/science.1124891

Nixon K.C. 2002. Winclada (BETA) ver. 1.00.08. Published by the author. Ithaca, New York.

Rambaut A., Suchard M.A., Xie D. \& Drummond A.J. 2014. Tracer v1.6. Available from http://tree.bio. ed.ac.uk/software/tracer/

Reis M. dos \& Yang Z. 2011. Approximate likelihood calculation on a phylogeny for Bayesian estimation of divergence times. Molecular Biology and Evolution 28: 2161-2172. https://doi.org/10.1093/molbev/msr045

Ronquist F. \& Huelsenbeck J.P. 2003. MrBayes 3: Bayesian phylogenetic inference under mixed models. Bioinformatics 19: 1572-1574. https://doi.org/10.1093/bioinformatics/btg180

Swofford D.L. 2002. PAUP*. Phylogenetic Analysis Using Parsimony (*and other methods). Version 4. Sinauer Associates, Inc. Publishers, Sunderland, Massachusetts. Available from http://paup.scs.fsu.edu/

Tamura K., Peterson D., Peterson N., Stecher G., Nei M. \& Kumar S. 2011. MEGA5: Molecular Evolutionary Genetics Analysis using maximum likelihood, evolutionary distance, 
HOSOISHI S. \& OGATA K., Phylogenetic position of two new Crematogaster ants

and maximum parsimony methods. Molecular Biology and Evolution 28: 2731-2739. https://doi.org/10.1093/molbev/msr121

Ward P.S. 2006. The ant genus Tetraponera in the Afrotropical region: synopsis of species groups and revision of the T. ambigua-group (Hymenoptera: Formicidae). Myrmecologische Nachrichten 8: 119130.

Ward P.S. \& Downie D.A. 2005. The ant subfamily Pseudomyrmecinae (Hymenoptera: Formicidae): phylogeny and evolution of big-eyed arboreal ants. Systematic Entomology 30: 310-335. https://doi.org/10.1111/j.1365-3113.2004.00281.x

Ward P.S., Brady S.G., Fisher B.L. \& Schultz T.R. 2015. The evolution of myrmicine ants: phylogeny and biogeography of a hyperdiverse ant clade (Hymenoptera: Formicidae). Systematic Entomology 40: 61-81. https://doi.org/10.1111/syen.12090

Ward P.S. \& Fisher B.L. 2016. Tales of dracula ants: the evolutionary history of the ant subfamily Amblyoponinae (Hymenoptera: Formicidae). Systematic Entomology 41: 683-693. https://doi.org/10.1111/syen.12186

Wheeler W.M. 1927. The physiognomy of insects. Quarterly Review of Biology 2: 1-36.

Yamane S., Tanaka O.H. \& Itioka T. 2011. Rediscovery of Crematogaster subgenus Colobocrema (Hymenoptera, Formicidae) in Southeast Asia. Zootaxa 2999: 63-68.

Yang Z. 2007. PAML 4: Phylogenetic Analysis by Maximum Likelihood. Molecular Biology and Evolution 24: 1586-1591. https://doi.org/10.1093/molbev/msm088

Zwickl D.J. 2006. Genetic algorithm approaches for the phylogenetic analysis of large biological sequence datasets under the maximum likelihood criterion. PhD thesis, The University of Texas, Austin.

Manuscript received: 30 November 2016

Manuscript accepted: 15 March 2017

Published on: 24 November 2017

Topic editor: Gavin Broad

Desk editor: Jeroen Venderickx

Printed versions of all papers are also deposited in the libraries of the institutes that are members of the EJT consortium: Muséum national d'Histoire naturelle, Paris, France; Botanic Garden Meise, Belgium; Royal Museum for Central Africa, Tervuren, Belgium; Natural History Museum, London, United Kingdom; Royal Belgian Institute of Natural Sciences, Brussels, Belgium; Natural History Museum of Denmark, Copenhagen, Denmark; Naturalis Biodiversity Center, Leiden, the Netherlands; Museo Nacional de Ciencias Naturales-CSIC, Madrid, Spain; Real Jardín Botánico de Madrid CSIC, Spain. 